\title{
Features of the introduction of ornamental herbaceous plants native to the Russian Far East region in Laboratory of Ornamental Plants, at Main Botanical Garden of Russian Academy of Science
}

\author{
Irina A. Bondorina, Alexander V. Kabanov, and Julia A. Khokhlacheva* \\ Tsitsin Main Botanical Garden of Russian Academy of Sciences, Moscow, Russia
}

\begin{abstract}
Based on a long-term introduction study of the species native to the Russian Far East region, a representative collection was collected, including a wide range of ecological groups. On the basis of the conducted research, the peculiarities of the preservation of individual species in the collection fund (the ability to persist in culture for a long time, vegetative renewal, self-seeding) are revealed. It is noted that for a number of species, in addition to active vegetative overgrowth, mass self-seeding is also noted. Despite the prospects of such species in the introduction work, they can pose a potential threat to invasion. That is why only those species that are not characterized by regular and mass self-seeding are recommended for use in urban landscaping.
\end{abstract}

\section{Introduction}

There is a unique place on the territory of the Russian Federation - the Far Eastern Federal District. The region occupies a huge space, with an area of approximately 3,1 million square kilometers, extending from north to south for 4,5 thousand kilometers. Various types of relief, subject to the predominance of mountainous territories, various types of soils from permafrost-taiga light-earth and tundra gley soil to brown forest and yellow-earthbrown, the monsoon nature of the climate and the peculiar history of the formation of flora caused the uniqueness of the floral composition of the region. So, according to V. N. Voroshilov, the flora of the Far East has about 3-3,1 thousand species [1-3].

Selection and introduction of promising species native to the Russian Far East region into the culture with the further possibility of introducing individual representatives into mass urban landscaping.

\section{Materials and methods}

*Corresponding author: jusic-la@yandex.ru 
In the process of forming, maintaining and expanding the collection fund of the laboratory of ornamental plants of the MBG RAS, 2 classical methods of introduction were mainly used: ecological-phytocenotic [4] and the method of generic complexes [5].

\section{Results and discussion}

The formation of collection funds of living plants of natural flora, promising for introduction study, has always been one of the tasks of the department (later - the laboratory) of ornamental plants of the MBG RAS. And of course, special attention was paid to the natural views of the Far East.

During the period from the moment of its foundation - 1945 to the present period, there are 3 stages of replenishing the collection funds with natural species of this region.

Stage 1 (from the foundation of the department in 1945-1946 to 1959) - the formation of collection funds by obtaining live plants and seeds from botanical institutions of the USSR and Germany. During this period of time, plants belonging to 14 families, 17 genera and 23 species were included in the collection [6].

Stage 2 (from 1960 to 1990) - the formation of collection funds mainly due to the collection of live plants and seeds in natural habitats (expeditions to the Far East). According to the data for 1983 [7] in the department of ornamental plants, plants belonging to 33 families, 55 species and 74 genera were introduced.

Stage 3 (from 1991 to the present day) - replenishment of collection funds mainly at the expense of seed delectus (with the exception of expeditions to the Primorsky Territory in 2005, 2019, as well as to Sakhalin Island in 2017). During this period [8] there is a further change in the structure of collection funds. So, at the end of 1999, plants belonging to 29 families, 62 genera and 85 species were represented in the collections of the department. In 2001-2008, there is a further increase in the number of studied samples [9]. According to the autumn inventory of 2020 the laboratory of ornamental plants presents plants of the flora of the Far East belonging to 35 families, 67 genera and 100 species [10].

Based on the ecological analysis of the available volume of introduced species, the predominant group is forest (63 species), followed by meadow (22 species) and species associated with scree and rocky habitats (15 species).

Plants of the Far East are exhibited at 2 sites - forest species at the territory of the collection-exposition «Shadow Garden» site, and representatives of other ecological groups - at the collection site of sparsely distributed perennials.

The introduction study of species is carried out both by the ecological and phytocenotic method [4] (at the collection-exposition «Shadow Garden» site) and by the method of generic complexes (at the exposition site of sparsely distributed perennials) [5]. At the same time, the Far Eastern species are not singled out separately, but are considered only in the aspect of generic complexes. This allows us to assess the prospects of a particular species within the genus. Cultivation of plants in the laboratory of ornamental plants on collection sites, taking into account regular measures for the care and rejuvenation of collection specimens, allows them to be preserved for a long period.

Based on many years of research, it can be concluded that many natural Far Eastern species are promising for culture, including for gardening in Moscow. For many species, seed renewal is noted, as well as the ability to natural vegetative renewal. There are many long-lived plants among the Far Eastern species. At the same time, among the tested plants, according to the features of self-support, 5 groups can be distinguished:

1. plants persist for a long time, but do not form self-seeding, there is no possibility of natural vegetative reproduction (except for the possibility of particularization) Aconogonon divaricatum (L.) Nakai ex Mori Cimicifuga simplex Wormsk., Osmundastrum claytonianum (L.) Tagawa, Sanguisorba magnifica Schischk. et Kom. 
2. plants persist for a long time, give a single self-seeding, there is no natural vegetative renewal - Hosta lancifolia Engl., Lysichiton camtschatcense (L.) Schott, Paeonia obovata Maxim., Saxifraga manchuriensis (Engl.) Kom., Symplocarpus foetidus (L.) Salisb. Ex Nutt.

3. plants persist for a long time, give mass self-seeding, there is no natural vegetative renewal (except in cases of particularization) - Ligularia dentata (A. Gray) Hara, $L$. fischeri (Ldb.) Turcz., L. hodgsonii Hook. f., Filipendula camtschatica (Pall.) Maxim., Sanguisorba tenuifolia Fisch. ex Link.

4. plants persist for a long time, do not self-seeding (or it is not detected), but are capable of natural vegetative renewal. At the same time, depending on the rate of growth, it is possible to distinguish:

4a - active development of the territory (aggressive species) - form loose thickets: Aconogonon weyrichii (F. Schmidt) H. Hara, Miscanthus sacchariflorus (Maxim.) Hack., Meehania urticifolia (Miq.) Makino, Thermopsis lupinoides (L.) Link.

$4 \mathrm{~b}$ - moderate development of the territory-form thickets (or curtains), are not aggressive: Aruncus asiaticus Pojark., Carex siderosticta Hance, Lysimachia clethroides Dybi, Onoclea sensibilis L., Astilbe chinensis (Maxim.) Franch. \& Sav.

5. plants living for 2-3 years, forming a mass self-seeding - Delphinium grandiflorum L., Campanula cephalotes Nakai.

Based on the available data, it is worth noting that species capable of active self-renewal can pose a real threat to the native flora. That is why the use of such types should be significantly limited.

\section{Conclusion}

The most promising for urban landscaping are long-lived species that are not prone to generative or vegetative renewal (group 1), or with a slight generative renewal (group 2), as well as species that are characterized by only moderate or slow vegetative growth (group $4 b)$.

Currently, the collection is being replenished with Far Eastern species. One of the most important tasks, in addition to the search for new species that have not been studied in our conditions, is to restore in the collections those species that have previously been introduced and have shown their prospects for cultivation in this region, but for a number of reasons have fallen out of the collection funds.

The work was carried out in accordance to Institutional research project №118021490111-5.

\section{References}

1. V. N. Voroschilov, Flora of the Soviet Far East (Moscow, Science, 1966)

2. V. N. Voroschilov, Far Eastern botanical expeditions of the Department of Flora of the USSR, Botanical and geographical regions of the USSR. Prospects of plant introduction (1974)

3. V. N. Voroschilov, Determinant of plants of the Soviet Far East (Moscow, Science, 1982)

4. N. V. Trulevich, Ecological and phytocenotic bases of plant introduction (Moscow, Science, 1991)

5. F. N. Rusanov, Bulletin of the MBG of the USSR Academy of Sciences. 7 (1950) 
6. Decorative perennials: brief introduction results (Moscow, Publishing house Acad. of Sciences of the USSR,1960)

7. Floral and ornamental herbaceous plants: brief results of introduction (Moscow, Science, 1983)

8. Catalog of collections of the department of ornamental plants (Moscow, Ales, 2000)

9. A. S. Demidov, Herbaceous ornamental perennials of the Main Botanical Garden RAS: 60 years of introduction (2009)

10. I. A. Bondorina, A. V. Kabanov, J. A. Khokhlacheva, Moscow University Biological Sciences Bulletin. 75 (2) (2020) 